\title{
A influência do gosto da cozinha portuguesa na História da alimentação no Brasil de Câmara Cascudo
}

\author{
The influence of Portuguese cuisine taste on History of \\ food in Brazil by Câmara Cascudo
}

Mariana Corção

O tema alimentar, entendido inicialmente enquanto necessidade vital do indivíduo, é revestido de sentido coletivo dentro da obra História da alimentação no Brasil de Luís da Câmara Cascudo, que foi publicada em 1967. Desde o início do século XX, período em que a sociedade brasileira começou a sentir os efeitos da modernização, já se apresentavam discursos contrários à influência estrangeira nos hábitos alimentares, seja em defesa do que se entendia como culinária tradicional, seja em defesa da organização de uma cozinha brasileira. Cascudo esteve atento aos hábitos alimentares brasileiros desde o início dos seus es-

Mariana Corção é doutoranda em História da Universidade Federal do Paraná (maricorcao@gmail.com). A pesquisa presente no artigo foi viabilizada pela bolsa concedida pela CAPES de estágio de doutorado sanduíche, realizado na Universidade de Lisboa entre setembro de 2011 e junho de 2012.

Artigo recebido em 21 de maio e aprovado para publicação em 6 de setembro de 2012. 
tudos no campo cultural na década de 1920. No contexto da década de 1950, observou a intensificação da influência da modernização nos hábitos alimentares, consequência da expansão da indústria alimentícia em todo o mundo ocidental através das campanhas de marketing - de fato, é possível afirmar que as propagandas exerceram forte influência nas preferências alimentares de diferentes grupos sociais (Rozin, 2001: 1483). Conjugando a vivência desses dois momentos históricos, Cascudo defende em sua história da alimentação uma historicidade alimentar que delineia uma culinária tradicional brasileira.

O período colonial é destacado em sua obra enquanto contexto incubador das tradições alimentares que experimentou em sua juventude. A cozinha dos colonizadores portugueses, nessa direção, recebe o papel central no processo histórico de elaboração da cozinha brasileira.

Um dos traços mais marcantes da escrita de Cascudo é a liberdade com que realizou exercícios etnográficos, o que se associa à sua identificação com o espaço do qual partem suas análises (Gonçalves, 2008: 2). A leitura do conjunto de sua obra, nessa direção, oferece o esboço de um autorretrato que tem como peça inicial sua vivência da infância no sertão do Rio Grande do Norte. Assim, se por um lado a memória individual motivou Cascudo e deu direcionamento a seus estudos, por outro, a cultura popular enquanto objeto de pesquisa fez com que encontrasse a si próprio no contexto analisado de tal forma que sua identidade pessoal aparece fundida na identidade coletiva apresentada em sua obra (Byington, 2000: 27).

A relevância concedida à continuidade de elementos culturais justifica a abordagem do presente artigo a partir das articulações entre tempo e distância como meio de ressignificação dos alimentos. Ressalta-se que dessa relação entre tempo e distância é despertada a saudade. Enquanto expressão única da língua portuguesa, a saudade remete ao período das navegações portuguesas e se integra à escrita histórica na luta contra o esquecimento assumido pelo romantismo europeu do século XIX (Albuquerque, 2010: 1, 7). Seguindo uma perspectiva romântica, Cascudo apresenta marcas nostálgicas em seus escritos. Entende-se que tais marcas exaltam elementos característicos da leitura do passado do contexto cascudiano, que é consequência da instabilidade diante da modernização e se refere à busca de uma identidade nacional brasileira (Albuquerque, 2010: $1-2)$.

Considerando que a formação do gosto alimentar individual congrega influências culturais e experiências pessoais (Rozin, 2001: 1479), o presente artigo propõe uma articulação de relatos da viagem de Cascudo a Portugal em 1947 com textos e memórias pessoais referentes à cozinha portuguesa em sua História da alimentação no Brasil, de forma a identificar influências de experiências gustativas individuais na narrativa histórica alimentar cascudiana. 


\section{Uma confissão a fazer}

Câmara Cascudo já havia apresentado interesse pela cultura alimentar brasileira anteriormente à escrita da História da alimentação no Brasil. A primeira obra em que faz apontamentos sobre o tema é Viajando o sertão, cuja primeira edição é de 1934. Neste livro o autor identifica na cultura sertaneja, alheia, no contexto, às influências da modernização, uma essência nacional pela preservação de aspectos históricos na vida cotidiana. A partir desse argumento, escreve em defesa da cozinha sertaneja, cuja preservação deveria passar por sua valorização dentro da cultura brasileira (Cascudo [1934] 2009: 40). A partir do exposto, considera-se que entre 1934 e 1963 Cascudo reuniu informações e discussões sobre a alimentação brasileira que foram compiladas em sua História $d a$ alimentação no Brasil, trabalho de caráter mais amplo e unificador escrito em favor da promoção da historicidade de alimentos que comporiam uma cozinha nacional. Ao longo desse período, destacam-se a influência de dois momentos históricos no direcionamento das discussões apresentadas por Cascudo-a modernização brasileira do início do século XX e o desenvolvimentismo da década de 1950.

É possível afirmar que a sensibilidade de Cascudo despertada diante da crescente transformação dos hábitos alimentares é um dos principais fatores que o levaram a eleger a temática alimentar. O autor nasceu em Natal, no Rio Grande do Norte, em 1898, passou a vida nesse espaço que caracterizava como "província” e lá faleceu em 1986. Situado, portanto, às margens do desenvolvimento econômico brasileiro do período (que era irradiado a partir da região Sudeste), assistiu com pesar, ao longo da vida, à transição de uma sociedade de costumes marcadamente rurais para uma sociedade urbanizada.

Atento ao caráter tradicional da alimentação brasileira, Cascudo desenvolve no primeiro volume da obra uma história alimentar dividida em três capítulos, nomeadamente: o cardápio indígena, a dieta africana e a ementa portuguesa. A cozinha brasileira, que analisa no segundo volume, é apresentada como uma miscelânea de alimentos e costumes relacionados ao período colonial, em que teria ocorrido a fusão de três grupos formadores, os quais são referidos como raças formadoras. A organização da pesquisa revela o alinhamento de Cascudo com o mito das três raças fundadoras oriundo de estudos interpretativos da identidade brasileira realizados no século XIX. Destaca-se também a influência dos estudos folclóricos de Sílvio Romero (Cascudo, 1954: 29).

No contexto do início do século XX, Cascudo dialogou com dois grupos de pensadores brasileiros que marcaram de forma significativa seu pensamento sobre a cultura brasileira. O primeiro grupo foi o Movimento Modernista, com o qual estabeleceu contato a partir de 1922, quando ainda cursava medicina no Rio 
de Janeiro. O segundo foi o Movimento Regionalista de Recife, cuja atividade começou em 1926 e foi encabeçado por Gilberto Freyre. O Movimento Moder-

nista do Sudeste despontou como resposta ao desejo de modernização da elite brasileira, que vinha desde meados do século XIX e se fortaleceu no início do século XX (Doin, 2007: 95). Intelectuais e artistas desse movimento dialogavam com ideais de modernidade da elite brasileira, abarcando contribuições artísticas de outros países, e repensando-as no sentido de constituir algo essencialmente nacional. Já os intelectuais do Movimento Regionalista do Nordeste, geograficamente localizados às margens do desenvolvimento brasileiro, exaltaram a tradicionalidade de cada região enquanto matéria essencial da unidade nacional (Albuquerque, 2009: 51). As tradições advindas dos tempos de riqueza colonial ganharam relevância ao serem integradas à base da cultura nacional então identificada nos tempos coloniais. Nessa perspectiva, Gilberto Freyre, no I Congresso Regionalista realizado em 1926, apontou o declínio dessas tradições como consequência do encantamento pelo moderno, destacando a questão a partir da culinária: “Toda essa tradição está em declínio ou, pelo menos, em crise, no Nordeste. E uma cozinha em crise significa uma civilização inteira em perigo: o perigo de descaracterizar-se" (Freyre, [1926] 1996: 54).

Para os intelectuais modernistas do Sudeste, Cascudo se tornou uma fonte de informações sobre a cultura nortista brasileira. Dessa forma, tornou-se correspondente e amigo de Mário de Andrade, com quem intercambiou ideias e informações a respeito do desafio da consolidação da cultura nacional. Sobre sua relação com esses dois movimentos, Cascudo afirmou numa entrevista à revista Veja, em 1972:

Pertencia ao grupo do Recife, mas vale lembrar que a revista Antropofágica e o verde-amarelismo valorizaram muito o folclore, o índio, o cotidiano, 'tupy or not tupy', dizia o doido mor Oswald de Andrade em plena confusão de 22, e que me abraçou com muito carinho pela minha preocupação em descrever o dia a dia do brasileiro.

Entende-se, a partir do exposto, que seu pertencimento ao grupo de Recife se deu como consequência de sua identidade pessoal, fundada em suas relações pessoais com a região. Cascudo demonstrou essa identificação, por exemplo, no prefácio da primeira edição de Vaqueiros e cantadores, em que escreveu: "Reúno nesse livro quinze anos da minha vida. (...) O material foi colhido diretamente na memória duma infância sertaneja, despreocupada e livre" (Cascudo, 1939: 5). Para Humberto Hermegenildo Araújo, são raros os momentos em que a 


\section{Mariana Corção}

produção de Cascudo se encontra em sintonia com o pensamento regionalista de Gilberto Freyre (Araújo, 2012: 90). Nesse sentido, consideramos que o registro da experiência etnográfica do lugar ao qual pertence, uma região estranha à intelectualidade modernista do Sudeste, motivou e autorizou a obra cascudiana. Sua atenção às particularidades do mundo que o envolvia esteve marcada tanto pela subjetividade quanto pelo contraste de quem buscava uma universalidade nas diferentes manifestações culturais.

Segundo essa perspectiva, ao identificar a relevância da cultura portuguesa na formação da cozinha brasileira, Cascudo pensa não somente em categorias sociológicas, etnográficas e históricas, como também numa dimensão psicológica que inclui a noção de gosto. $\mathrm{O}$ paladar é entendido como um mecanismo que associa a memória de sabores com a química corporal da identificação destes (Cascudo, [1967] 2004a: 370). As preferências alimentares dos grupos sociais estão diretamente ligadas às tradições culinárias desses grupos. Destaca-se, nesse sentido, que Cascudo reconhece a presença da cozinha colonial luso-brasileira no "sertão das eras de setecentos" que vivenciou na infância (Cascudo, 1939: 5).

A noção de gosto em Cascudo funde indivíduo e coletivo. Ao se reconhecer enquanto membro do coletivo, inclui fragmentos de sua memória pessoal na análise que elabora das tradições culinárias brasileiras. Dessa forma, confessa em História da alimentação no Brasil: "e eu, ainda que me valha a confissão os desagrados de alguma leitora elegante, francamente declaro aqui que, para mim, a cozinha portuguesa é das melhores cozinhas do mundo" ([1967] 2004a: 330).

\section{Tempo: condimento essencial}

O gosto pela cozinha portuguesa se associa à marca tradicionalista com que Cascudo a identifica. Manifesta sua admiração por ela por sua humildade e obstinação diante dos apelos da modernidade da indústria alimentícia em expansão ([1967] 2004a: 334). A continuidade dos alimentos no tempo aparece na obra cascudiana como fator determinante na constituição do paladar social. Nesse sentido, pode-se ponderar sobre o papel conferido às tradições em sua história da alimentação na determinação das preferências alimentares brasileiras.

Por ocasião do I Congresso Luso-Brasileiro de Folclore, em 1947, Cascudo pisou em solo português pela primeira vez. Sua viagem por Portugal durou cerca de um mês. Partiu do Brasil pelo porto do Rio de Janeiro, desembarcou na Espanha e seguiu de trem até Portugal. Assim, Valença, vila do extremo norte português, marcou sua primeira experiência portuguesa. Ao longo da estada em Portugal, Cascudo enviou textos relatando o diário da viagem que foram publicados no Diário de Natal. No quarto "bilhete", publicado em 15 de setembro de 
1947, registrou sua primeira refeição portuguesa em Valença: almoço com vinho verde, galinha de arroz ao forno e pescada frita (apud Marinho, 2004).

De Valença seguiu até Lisboa, passando por Vila Nova de Cerveira, Caminha, Viana do Castelo, Barcelos, Esposende (onde, na divisão administrativa da época, acabava a região do Minho e começava a região do Douro), Póvoa de Varzim, Mindelo, Lonzã, Bouças, Porto, Vila Nova de Gaia, Leixões, Praia do Espinho, Ovar (onde começa a região da Beira), Angeja, Albergaria-a-Velha, Aveiro, Vagos, Figueira da Foz, Leiria, Batalha, Porto de Mós (onde tem início a Estremadura), Alcobaça, Caldas da Rainha, Vila Franca de Xira e Sacavém. Durante sua estada em Lisboa conheceu Sintra, Torres Vedras, Varatojo, Palhavã e Queluz. Seguiu em viagem por uma rota desde Lisboa até o interior do país, passando por Alenquer, Caldas da Rainha, Alcobaça, Batalha, Fátima, Tomar, Abrantes, Proença-a-Nova, Castelo Branco (então capital da região da Beira Baixa), Monsanto, Nisa, Alpalhão, Portalegre, Monforte, Estremoz, Borba, Vila Viçosa, Redondo, Évora, Montemor-o-Novo, Vendas Novas, Setúbal, Portinho da Arrabida, Cabo Espichel, Sesimbra e Cacilhas. Passou o período final na cidade do Porto, de onde partiu para conhecer Vila do Conde, Póvoa do Varzim, Viana do Castelo, Coimbra, Ponte do Lima e Barcelos (Marinho, 2004: 11-13).

Nas expressões de suas experiências manifestadas em seus bilhetes de viagem é possível visualizar alguns aspectos relevantes de sua análise alimentar. No décimo bilhete escreveu: “Só meus dias europeus ('excusez...') podem dar uma impressão que é impossível no continente americano. Impossível mesmo para a compreensão psicológica. É a impressão do Tempo, o Tempo como uma dimensão, um elemento real, verídico, sensível, material" (apud Marinho, 2004).

O tempo é uma problemática muito cara na vida e na obra de Cascudo. Tinha 27 anos quando manifestou numa correspondência de 1925 a Mário de Andrade: "Perdoe V. o papel. Estou no meio de vaqueiros e cantadores. Não há luz elétrica. A coisa que me lembra, e detestavelmente o progresso, é o meu Ford que está parado debaixo do telheiro" (apud Moraes, 2010: 60). O comentário sugere uma visão pessimista da noção de progresso, este último entendido como um meio de renovação da cultura material e dos hábitos e como um fator que materializa e destaca o contraste da passagem do tempo. Cascudo associa o progresso a um movimento de uniformização e banalização de uma cultura moderna que reinventa o sertão tradicional de sua infância. Um sertão, segundo seu relato, onde se vivia até a invasão da modernidade costumes e hábitos sobreviventes desde o século XVIII (Cascudo, 1939: 5-6). Entre esses hábitos, Cascudo identifica a culinária como a tradição mais fiel, conforme posteriormente afirmou no prefácio da História da alimentação no Brasil: "Para o povo não há argumento probante, técnico, convincente, contra o paladar..." (Cascudo, [1967] 2004a: 15). 
Identificar na comida popular um dos meios de permanência de tradições mais persistentes num contexto de crescente transformação dos hábitos decorrente da modernização não é um privilégio da análise cascudiana. No Brasil, Gilberto Freyre já havia chamado a atenção para relevância das tradições alimentares no Manifesto regionalista de 1926, conforme já citado.

Da desestabilidade resultante da modernização decorreu que pensadores focassem nos costumes em processo de transformação. A alimentação, nesse contexto, foi percebida como o meio mais resistente de tradições. Dessa forma, destacam-se inicialmente, entre a produção de folcloristas no início do século $\mathrm{XX}$, os estudos relacionando tradição e alimentação.

Os estudos de folclore despontaram na Inglaterra em meados do século XIX, num contexto em que se buscava uma identidade do povo como meio de legitimar a democracia na Europa (Ramos, 2003: 25). Assim, os modos de vida populares, as línguas, os usos e os costumes são ressaltados em associação ao valor romântico da cultura camponesa. Marcado fundamentalmente por uma essência ruralista, o movimento folclórico se institucionaliza e se reproduz em quadros urbanos em diferentes países (Castelo Branco e Branco, 2003: 7). A institucionalização do movimento está associada a dois elementos simbólicos relevantes para o nacionalismo do período, o valor concedido às memórias do passado comum e a preocupação com a perpetuação do legado identitário de grupos sociais $(\mathrm{Ca}-$ bral, 2011: 61). Os trabalhos sobre alimentação provenientes desse meio apresentam um caráter etnográfico, consistindo num levantamento de características da alimentação popular, identificada na correlação entre a geografia do país e o cultivo das terras e nos hábitos e costumes alimentares tradicionais.

No I Congresso Internacional de Folclore realizado em Tours, na França, em 1938, destacam-se duas apresentações que enfatizam a alimentação popular, a do historiador Lucien Febvre e a do grupo brasileiro da Sociedade de Etnografia e Folclore. No estudo apresentado sobre as repartições geográficas dos fundos da cozinha na França, Febvre argumentava que a estabilidade da alimentação é relativamente fixa, uma vez que não é sem dificuldade que os homens aceitam um alimento novo (Febvre, 1938: 124). O grupo brasileiro, encabeçado por Mário de Andrade e Dina Lévi-Strauss, apresentou uma pesquisa cartográfica sobre tabus alimentares e danças populares brasileiras (Shimabukuro et al., s.d.: 7).

Apesar das influências da produção intelectual do contexto, as pesquisas realizadas por Cascudo apresentam características muito próprias. Esse fato se relaciona com a perspectiva com que trabalha, não sobre a cultura popular, mas a partir desta (Gonçalves, 2004: 2). É possível afirmar, nessa perspectiva, que seus estudos sejam motivados pela sensibilidade despertada pela fluidez da vida material e dos costumes tradicionais observados em tempos de renovação. 
O tempo, dessa forma, é tido nas análises cascudianas como um fator de caracterização e descaracterização da cultura popular. É na dinâmica da passagem do tempo que se funda sua fala em favor das tradições (Silva, 2006: 202). Assim, o costume popular é enriquecido ao longo da passagem dos anos, convertendo-se em conteúdo folclórico. A experiência de Cascudo com os pastéis de Belém da tradicional pastelaria de Lisboa, fundada em 1832, revela essa tendência: "o tempo valoriza esses pastéis de tal forma que ir comê-los é o mesmo que praticar um ato de proclamada inteligência reverenciadora" (Cascudo, 1947, apud Marinho, 2004: 52-53).

É relevante destacar que no contexto da estada de Cascudo em Portugal a política do Estado Novo português (1933-1974), encabeçada por Salazar, promovia estudos folclóricos como meio de divulgação de ideologias do regime associadas a uma nostalgia rural (Branco, 2003: 234). Desde a década de 1930, o regime salazarista mobilizava-se para institucionalizar a portugalidade através da valorização do tesouro comum constituído por imagens, objetos, ritos e crenças populares, que tinha como base as narrativas históricas (Serrão e Marques, 1992: 394). Aproximações ideológicas entre o Estado Novo brasileiro (1937-1945) e o português estreitaram os laços entre as duas nações. Nesse sentido afirma Joaquim Serrão que "em poucas épocas da história luso-brasileira se fez sentir tanto a irmandade do sentimento baseado na língua comum, como no decênio de 1940" (2003: 364). Dentro desse contexto, a valorização da herança cultural da colonização portuguesa na obra de Cascudo foi bem recebida, por ir ao encontro das políticas culturais do Estado português.

Fundamentado pela tríade Deus, pátria e família, o Estado Novo português, através de políticas educacionais, incentivou a produção agrícola do país, assim como instigou o mundo feminino a assumir com destreza as tarefas de casa. Esses dois fatores cooperaram para a permanência de tradições culinárias. Assim, apesar da crescente modernização no mundo ocidental, muitos portugueses do período estavam convencidos de que a alimentação rural era melhor e mais humanizada que a da cidade (Cascão, 2011: 62).

O governo salazarista promoveu, no ensino básico feminino, a economia doméstica enquanto "ciência da felicidade e da prosperidade da família" (Braga, 2008: 120-121). A matéria era destinada às alunas da terceira e quarta classes (atuais terceiro e quarto anos do ensino básico), sendo que no quarto ano todo o conteúdo da matéria estava relacionado à alimentação. As alunas aprendiam a escolher os alimentos, maneiras de conservá-los, receitas de ovos, sopas, carnes e peixes, além de receber conselhos sobre compras (Braga, 2008: 121).

A ideologia do regime se fazia presente até mesmo nos livros de cozinha publicados no período. Ressalte-se que em Portugal, até o início do século XX, as publicações de matéria gastronômica eram assinadas por homens (os consagra- 


\section{Mariana Corção}

dos chefs). A partir da política de valorização da mulher como fada do lar, as mulheres começaram a se destacar como autoras de publicações. Nos livros de culinária desse contexto, como o popular $A$ cozinheira das cozinheiras, de Rosa Maria, que foi publicado na década de 1930 (com a grafia cosinheiras) e teve 30 edições até 1982, novas maneiras de cozinhar elementos presentes na cultura alimentar portuguesa (como sopa, bacalhau e ovos, por exemplo) foram apresentadas, em associação com os valores de poupança, nutrição e higiene (Braga, 2008: 128). Dessa forma, a alimentação tradicional não somente foi valorizada, como permaneceu no cotidiano das famílias portuguesas. Entre os alimentos que agregaram forte significado social nesse contexto, destacou-se a doçaria tradicional portuguesa. Pela originalidade, sobretudo no que se refere à cozinha conventual, a doçaria foi consagrada como elemento da identidade nacional portuguesa.

A doçaria portuguesa atingira seu auge ao longo do século XVIII, como consequência da simbiose mercantilista da produção açucareira do Brasil no período (Algranti, 2005: 147), e revelava também uma ligação significativa entre a cozinha e a agricultura portuguesas. Nesse sentido, além da presença de alguns produtos do além-mar, como o açúcar e as especiarias, canela e cravo, por exemplo, destacavam-se os produtos regionais do campo português, como ovos, farinha de trigo, manteiga, queijo fresco, mel, amêndoas, nozes, chila, ${ }^{1}$ feijão bran$\mathrm{co}^{2}$ limão e laranja, como os principais componentes dos doces tradicionais. Entre os autores portugueses que elaboraram estudos etnográficos sobre a doçaria tradicional citados por Cascudo em História da alimentação no Brasil, destacam-se Emanuel Ribeiro, autor de o Doce nunca amargou (1923), e Luís Chaves, autor do artigo $O$ significado social da doçaria (1948).

Em seu livro, Emanuel Ribeiro caracteriza o povo português como tradicional por não dispensar o consumo cotidiano dos doces tradicionais. $\mathrm{O}$ autor destaca que esse hábito, fixado ao longo do século XVIII, permaneceu mesmo após a revolução liberal que fechou grande parte dos conventos no século XIX. As receitas dos conventos foram vendidas na ocasião, e os doces passaram a ser comercializados nas pastelarias. A presença da tradição culinária, contudo, conviveu no início do século XX, segundo Emanuel Ribeiro, com um crescente processo de desnacionalização a partir da influência modernizadora estrangeira (Ribeiro [1923], s.d.: 53-54)

Tratando do mesmo objeto, Luís Chaves destaca em seu artigo aspectos sociais da doçaria tradicional, como a importância da apresentação dos doces, as ocasiões em que são feitos, as diferenças entre a doçaria rústica e a doçaria requintada. Na perspectiva desse autor, a doçaria acompanhou as transformações dos costumes, e por isso continuou a ter uma íntima relação com a sociedade portuguesa mesmo em tempos de comercialização pelas pastelarias. Numa análise otimista, Chaves argumenta que as casas tradicionais de comércio resguardam o receituário antigo e promovem relações sociais (Chaves, 1948: 320). 
Em diálogo com esses autores, Cascudo afirma no capítulo Ementa portuguesa de sua história da alimentação que "quem viaja a Portugal na segunda metade do século XX verifica a capitosa perseverança de sua culinária conservadora" (Cascudo, [1967] 2004a: 334). Nessa perspectiva, entende-se que o reconhecimento que faz da cozinha portuguesa como uma das melhores cozinhas do mundo está relacionado com a identificação de sua tradicionalidade e de sua simplicidade, no sentido de que se mantém ligada à produção agrícola local.

Entre os diversos doces que Cascudo experimentou em sua viagem a Portugal, destacam-se os fartes, ou farteis, doce classificado em História da alimentação no Brasil como histórico (juntamente com as queijadinhas de amêndoas, o manjar-branco e o pão-de-ló). Esse doce de tradição medieval, feito de farinha de trigo, especiarias e mel, é recorrentemente citado na literatura histórica portuguesa listada pelo pensador potiguar. Entre as menções, a mais relevante nessa história alimentar brasileira é a carta de Pero Vaz de Caminha. Tendo por fundamento esse documento histórico, os farteis são destacados por Cascudo como "o primeiro doce que um brasileiro comeu no Brasil" (Cascudo, [1967] 2004a: 311).

A relevância histórica dos farteis, nesse sentido, parece influenciar a experiência do gosto, segundo se pode observar no relato de Cascudo ([1967] 2004a: 311): "quando, em novembro de 1947, o comi em Portugal, senti-me contemporâneo de todos os amerabas tupiniquins do meu país". Essa frase denota uma relação entre a consciência da historicidade do alimento com a sensação despertada pela experiência gustativa. Entende-se, nesse sentido, que a experiência vivenciada por Cascudo ao experimentar os farteis se deve a uma consciência prévia que tinha do caráter histórico desse doce.

$\mathrm{O}$ valor da historicidade dos alimentos identificada na obra de Cascudo se associa ao seu entendimento do discurso histórico enquanto base referencial do valor simbólico anexo às tradições. É interessante ressaltar no caso dos farteis que, apesar de constarem nas primeiras referências da doçaria portuguesa no Brasil, não tinha seu consumo associado às tradições brasileiras contemporâneas a Cascudo ([1967] 2004a: 319). Assim, a viagem a Portugal viabilizou uma "revivência" histórica do sabor que os ameríndios sentiram no episódio da chegada dos portugueses.

\section{Distância: argumento contrastante}

O texto de Cascudo revela uma ânsia em experimentar hábitos e costumes relacionados com as origens de seus próprios hábitos e costumes, distantes temporalmente e/ou geograficamente. Nesse sentido, cabe a citação de Ilza Sou- 


\section{Mariana Corção}

za, que considera que Cascudo "vive em retiro, retirando" (S ouza, 2006: 47). Essa ânsia pode ser entendida como fruto de uma sensibilidade análoga à dos românticos do século XIX, que se sentiam nostálgicos de uma relação estreita que unisse o homem à natureza e aos outros homens (Maffesoli, 1997: 99).

O paradoxo situado entre a busca da união de costumes populares nas fronteiras brasileiras e de uma universalidade do ser é uma constante do pensamento cascudiano. Nessa perspectiva, o típico é sempre regional para Cascudo, enquanto o nacional já evidencia um plano de universalidade (Cascudo, 1984: 176). Seja temporalmente, seja geograficamente, seus estudos perpassam a problemática da distância. Desse paradoxo, desponta um tom nostálgico associado a um espaço-tempo em que o sentido do ser aparece atrelado a uma vida de solidariedade ligada à natureza. Espaço-tempo que Cascudo identifica nas lembranças dos tempos vividos no sertão de sua infância.

A identificação que Cascudo encontra com o lugar em que localiza suas origens marca todo o seu pensamento. Pode-se dizer que não somente a cultura popular do sertão, mas sobretudo o ambiente familiar em que cresceu foi um forte fator de influência em suas análises. Cascudo era o filho mais novo de três; os dois irmãos mais velhos, contudo, morreram ainda crianças, antes que ele nascesse. Enquanto filho único de saúde frágil, cresceu entre os adultos e os livros, rodeado de atenção e cuidados. Considerando que a família estabelece um vínculo irreversível entre a criança e o mundo, uma vez que em nenhum outro ambiente o lugar do indivíduo é tão fortemente determinado (Bosi, 1994: 423-425), pode-se dizer que as vivências da infância de Cascudo suscitaram seu interesse pela história de todas as coisas, do campo e da cidade, despertadas pela convivência com a "sua gente".

Em sua vida em família na província e na relação com a terra e as pessoas, Cascudo reconhece o sentido inicial de ser. Os fundamentos de sua própria identidade marcam definitivamente seus escritos, conforme declarou: "Jamais abandonei o caminho que leva ao encantamento do passado. Pesquisas. Indagações. Confidências que hoje não têm preço. [...] Impossível, para mim, dividir conterrâneos em cores, gestos de dedos, quando a terra é uma unidade com sua gente. Foram os motivos de minha vida expostos em todos os livros" (Cascudo, 2012: 6-7).

As tradições orais de seus conterrâneos estavam entre seus principais interesses. Nessas narrativas, Cascudo reconhecia conhecimentos adquiridos pela vivência. Eram a matéria principal dos seus estudos folclóricos. Nos mitos e lendas populares identificava elementos da memória coletiva, da recordação de um passado comum caracterizado em sua obra por sua ligação com lendas e mitos de outros lugares, pela universalidade (Cascudo, 1984: 35). 
Dentro dessas análises das tradições orais que revelam o contato das pessoas entre si e o contado destas com a terra, Cascudo manifesta o interesse pela comida enquanto matéria de estudo. Encontra no texto $A$ cozinha portuguesa, escrito pelo literato português José Valentim Fialho de Almeida em 1891, um forte argumento para a sua história da alimentação: "um povo que defende os seus pratos nacionais, defende o seu território" (Almeida, 1925, apud Cascudo [1967] 2004a: 378). A relevância do texto é tal que mereceu entrar no apêndice da obra de Cascudo.

Fialho de Almeida, que viveu entre os anos de 1857 e 1911, tem um enquadramento literário semelhante ao de Cascudo nas ciências humanas, e incorpora de maneira sui generis diferentes correntes estético-literárias como meio de expressão de uma individualidade artística própria. Pela marca subjetiva de seus textos, sua base inicial romântica nunca desaparece ao longo dos anos, mas atualiza-se (Revez, 2011: 394). A partir do seu romantismo, Fialho de Almeida define o prato nacional como "o romanceiro nacional, um produto do gênio coletivo: ninguém o inventou e inventaram-no todos: vem-se ao mundo chorando por ele, e quando se deixa a pátria, lá longe, antes de pai e mãe, é a primeira coisa que lembra".

Conjugando sentimentos de coletividade, alteridade e saudade, o conceito de prato nacional de Fialho de Almeida abarca tanto ideais românticos quanto nacionalistas. No contexto do pensamento nacionalista do século XIX, a elaboração de discursos em torno de cozinhas nacionais ocorre concomitantemente ao processo de construção simbólica dos Estados Nacionais europeus (Laurioux \& Bruegel, s. d: 18). Nesse contexto, a máxima atribuída a Brillat-Savarin - "Dis-moi ce que tu manges, je te dirai ce que tu es" [Dize-me o que comes e te direi quem és] -, registrada em sua obra Fisiologia do gosto, de 1825, ganha relevância em sua associação entre alimentação e identidade. A cozinha enquanto prática cultural coletiva e meio de transmissão de tradições passa a ser apresentada nesses discursos como meio que proporciona identidade aos indivíduos e defende o território nacional.

A noção da cozinha como um sistema integrado a uma estrutura social foi inicialmente defendida pelo antropólogo francês Claude Lévi-Strauss. Nessa perspectiva, enquanto expressão parcial da estrutura de funcionamento de grupos sociais, a cozinha se revela como uma linguagem que traduz mecanismos de funcionamento da sociedade a que pertence (Lévi-Strauss, 1996: 98-99). A cozinha passou, então, a ser entendida enquanto símbolo identitário que constitui, mais do que um conjunto de tradições culinárias, um meio através do qual as pessoas podem se orientar e se distinguir (Maciel, 2004: 36).

Em História da alimentação no Brasil Cascudo não faz referências diretas a obras de Lévi-Strauss, mas é possível afirmar que teve contato com a pesquisa etnográfica que este realizou em companhia de sua esposa Dina Lévi-Strauss no 


\section{Mariana Corção}

Brasil. ${ }^{3}$ Em contraste com a antropologia estruturalista de Lévi-Strauss, que apresenta métodos de pesquisa com o objetivo de formular modelos que desvendem formas comuns nas manifestações sociais e de atribuir significado a estas (Lévi-Strauss, 1996: 399-400), Cascudo justifica a ausência de método em suas pesquisas como uma estratégia didática (Cascudo, 2004b: 15). Nessa perspectiva, o pensador brasileiro se recusa a enquadrar seus estudos no âmbito da antropologia cultural, apesar de possuir objetos comuns de pesquisa com essa área. Para sua obra, prefere a classificação folclórica, que Lévi-Strauss entende, em sua relação com a antropologia, como estudos de natureza arcaica que focam no caráter coletivo e inconsciente de certas atividades sociais. Seja pelo objeto, seja pelo método, o folclore se conecta com a antropologia, sem atender, contudo, à missão dos estudos antropológicos (Lévi-Strauss, 1996: 393).

A etnografia, para Cascudo, se define enquanto o estudo das origens, a partir da observação de continuidades contemporâneas que fazem referência às memórias da grande família humana (Cascudo, 2004b: 26). Desse entendimento decorre uma pesquisa que se funde com uma busca de si mesmo, de suas próprias origens enquanto membro dessa grande família. Ao dar relevo à memória social, Cascudo inclui de forma significativa as suas próprias memórias, alargando o papel de sua subjetividade em suas análises.

Destaca-se, nesse sentido, seu relato sobre a experiência dos pastéis de Belém, doce vendido na Pastelaria de Belém desde 1832. Esses pastéis são semelhantes ao tradicional pastel de nata português, e a diferença entre as duas receitas é um segredo da antiga pastelaria. Em seu relato, Cascudo mostra ter experiências anteriores de pastéis de nata em Natal:

Em Belém, antes do convento dos Jerônimos, há confeitaria, toda enfeitada de azulejos. Vende-se aí o famoso 'pastel de Belém'. O pasteleiro do convento tinha o segredo desses pastéis. Expulsos os frades, o pasteleiro fundou uma casa e começou a fazer e vender os pastéis. A casa atual data de 1832, data num cartel de azulejo. Milhares de pastéis são comidos diariamente. Nunca se soube, até hoje, o segredo da fabricação. Há um 'it' de mistério no sabor somente obtido pela casinha de Belém. $O$ tempo valoriza esses pastéis de tal forma que ir comêlos é o mesmo que praticar um ato de proclamada inteligência reverenciadora. Já tenho ido, várias vezes, reverenciá-los dignamente. Lembram, ao de longe, os nossos pastéis de nata (Cascudo, 1947, apud Marinho 2004: 52-53).

Ao comentar o gosto dos tradicionais pastéis de Belém, Cascudo os compara com "os nossos pastéis de nata". Essa colocação denota que a experiência da 
alteridade na viagem a Portugal tem como principal ponto comparativo suas próprias memórias.

Em História da alimentação no Brasil, Cascudo menciona a que pastéis de nata se referiu na ocasião da viagem: os que eram feitos pelas senhoras de "Natal Velho". Tal alusão se associa com a singularidade, defendida por Cascudo, que certas iguarias têm no contexto natural de sua criação, como os ovos moles de Aveiro ou a moqueca de peixe de Salvador: "Inútil a memória para reconstruí-las, distantes da paisagem telúrica de seu feitio tradicional” (Cascudo [1967], 2004a: 304). A partir desse discurso, ele conduz o leitor para o gosto excepcional dos pastéis de nata feitos por Dona Wanderley em Natal Velho, que, na sua opinião, eram inigualáveis. Cascudo ressalta a experiência culinária das doceiras experientes, que escapa a qualquer registro "científico", e destaca um gosto pessoal, fruto de uma experiência localizada em determinado espaço- tempo.

A referência aos pastéis de nata inigualáveis de Dona Wanderley e a designação de Natal Velho remetem a tempos anteriores à intensificação da modernidade na região em que vivia. A angústia diante da sucessão de novidades é compartilhada por Cascudo na exaltação de elementos culturais distantes no espaço-tempo. Dentro dessa abordagem, o gosto inigualável de um doce tradicional português, produzido e experimentado no Rio Grande do Norte em períodos anteriores "à chegada da modernidade na região", congrega significância na composição da história alimentar brasileira por ele elaborada.

\section{Considerações finais}

A saudade enquanto expressão da língua portuguesa funde sentimentalmente colonizados e colonizadores e desperta os sentidos para sensações que parecem se distanciar com a passagem do tempo no período de transformações. Ao experimentar os tradicionais pastéis de Belém portugueses durante sua estada em Lisboa em 1947, Cascudo é conduzido a outro espaço-tempo no qual ele próprio é o protagonista. Sua memória do sabor dos pastéis de nata de Natal Velho, nesse sentido, corrobora as motivações que o levam a pensar a alimentação brasileira numa perspectiva histórica. O valor simbólico do gosto e sua relação com a materialidade do alimento, no contexto da modernização, geram discursos em defesa da cozinha tradicional, uma vez que a continuidade de seu sabor depende intrinsecamente de sua continuidade material. A experiência individual do gosto e da saudade se integra em discursos sobre o coletivo. Assim, em História da alimentação no Brasil, Cascudo destaca a influência das tradições sociais na determinação das preferências alimentares. Nessa obra, a cozinha portuguesa é prestigiada tanto por sua relação com a história brasileira quanto por sua tradicionalidade e simplicidade no 


\section{Mariana Corção}

contexto de modernização do século XX. Na perspectiva de Cascudo, a cozinha tradicional brasileira tem como base a cozinha tradicional portuguesa. $O$ gosto e a saudade, nesse sentido, congregam sua história alimentar em favor da continuidade de ambas as cozinhas tradicionais que tanto apreciava.

Notas

1. Abóbora pequena da qual se faz o doce que é usado na feitura de Barcelos e Clarinhas, por exemplo.

2. O purê de feijão branco com amêndoa compõe o recheio dos pastéis de feijão.

3. Em carta dirigida a Mário de Andrade em 11 de dezembro de 1937, Cascudo pe-

Referências bibliográficas

ALBUQUERQUE, Durval Muniz de. $A$ invenção do Nordeste e outras artes. São Paulo: Cortez, 2009.

As sombras do tempo: a saudade como maneira de viver e pensar o tempo e a história. Disponível em: http://www.cchla. ufrn.br/ppgh/docentes/durval/index2.htm. Último acesso: 17 nov. 2010.

ALMEIDA, José Valentim Fialho de. Os gatos. Edições livros de Portugal. Rio de Janeiro, 1925, apud CASCUDO, Luís da Câmara. História da alimentação no Brasil. [1967] São Paulo: Editora Global, 2004.

ALGRANTI, Leila Mezan. Os doces na culinária luso-brasileira: da cozinha dos de-lhe que lhe envie o trabalho de LéviStrauss, possivelmente se referindo à obra Instruções práticas para pesquisas de antropologia física e cultural, de Dina Lévi-Strauss, que foi publicada em 1936 (apud Moraes, 2010: 298-299).

conventos à cozinha da casa "brasileira", séculos XVII a XIX. Anais de História AlémMar. Lisboa, vol. VI, 2005.

ARAÚJO, Humberto Hermegenildo. O ecritor Câmara Cascudo. Disponível em: http://hhermenegildo.50webs.com/O\%20 escritor\%20Camara\%20Cascudo.pdf. Último acesso: 10 set. 2012.

BOSI, Eclea. Memória e sociedade: lembrança de velhos. São Paulo: Companhia das Letras, 1994.

BRAGA, Isabel M. R. Drumond. Culinária no feminino: os primeiros livros de receitas escritos por portuguesas. Caderno Espaço Feminino. Uberlândia, vol. 19, n. 1, 2008. 
BRANCO, Jorge Freitas. Uma cartilha portuguesa: entre militância cultural e doutrinação política. In: CASTELO-BRANCO, Salwa El-Shawn \& BRANCO, Jorge Freitas. Vozes do povo: a folclorização de Portugal. Oeiras: Celta, 2003.

BYINGTON, Silvia Ilg. Pentimentos modernistas. As cores do Brasil na correspondência entre Luis da Câmara Cascudo e Mário de Andrade. Dissertação (Mestrado em História). Pontifícia Universidade Católica do Rio de Janeiro. Rio de Janeiro, 2000.

CABRAL, Clara Bertrand. Patrimônio cultural imaterial. Convenção da Unesco e seus contextos. Lisboa: Edições 70, 2011.

CASCÃO, Rui. À volta da mesa: sociabilidade e gastronomia. In: MATTOSO, Joel (dir.). História da vida privada em Portugal. A época contemporânea. Portugal: temas e debates, 2011.

CASCUDO, Luís da Câmara. Correspondência. In: MORAES, Marcos Antonio de (org.). Câmara Cascudo e Mário de Andrade: cartas, 1924-1944. São Paulo: Global Editora, 2010. . Viajando o sertão. [1934] São Paulo:
Editora Global, 2009.

Vaqueiros e cantadores. Folclore poético do sertão de Pernambuco, Paraíba, Rio Grande do Norte e Ceará. Porto Alegre: Globo, 1939.

Textos. Diário de Notícias, Natal, 1947. In: MARINHO, Francisco Fernandes. Câmara Cascudo em Portugal e o I Congresso Luso-Brasileiro de Folclore. Natal: Nordeste, 2004.

- Dicionário do folclore brasileiro. Rio de Janeiro, 1954.

Prefácio. In: ROMERO, Silvio. Cantos populares do Brasil. Tomo 1. Edição anotada por Luís da Câmara Cascudo. Rio de Janeiro: José Olympio, 1954.
A cozinha africana no Brasil. Luanda: Publicações do Museu de Angola, 1964.

História da alimentação no Brasil. [1967] São Paulo: Global, 2004a.

Folclore no Brasil. São Paulo/Lisboa: Fundo de Cultura, 1967.

O folclore está vivo. Entrevista. Veja, São Paulo, n. 189, p. 3-5, 19 abr. 1972.

Literatura oral no Brasil. Belo Horizonte: Itatiaia/São Paulo: Edusp, 1984.

. Civilização e cultura. Pesquisa e notas de etnografia geral. São Paulo: Global, 2004b.

-. Provinciano incurável. Disponível em: http://www.revista.agulha.nom. br/Diatahy\%20-\%20Cascudo.pdf. Último acesso: 16 abr. 2012.

CASTELO-BRANCO, Salwa El-Shawn \& BRANCO, Jorge Freitas. Vozes do povo: a folclorização de Portugal. Oeiras: Celta, 2003.

CAVALCANTI, Maria Laura Viveiros de Castro \& VILHENA, Luís Rodolfo da Paixão. Traçando fronteiras: Florestan Fernandes e a marginalização do folclore. Estudos Históricos, Rio de Janeiro, vol. 3, n. 5, 1990.

CHAVES, Luís. O significado social da doçaria. In: BASTO, Hermínia (org.) Miscelânea de estudos à memória de Cláudio Basto. Porto: Imprensa Portuguesa, 1948.

DOIN, J. E. de M. et al. A Belle Époque caipira: problematizações e oportunidades interpretativas da modernidade e da urbanização no mundo do café (1852-1930) - a proposta do Cemuc. Revista Brasileira de História. São Paulo, vol. 27, n. ${ }^{\circ}$ 53, 2007.

FEBVRE, Lucien. Répartition géographique des fonds de cuisine en France. In: Travaux du ler Congrès International de Folklore, Tours, 1938. 
FREYRE, G. Manifesto regionalista. [1926] Recife: Fundaj/Editora Massangana, 1996.

GONÇALVES, José Reginaldo Santos. A fome e o paladar: a antropologia nativa de Luís da Câmara Cascudo. Estudos Históricos, Rio de Janeiro, n. 33, 2004.

. A etnografia como auto-retrato: espaço, tempo e subjetividade em Luís da Câmara Cascudo. IX Congresso Internacional da BRASA, New Orleans, março de 2008.

LAURIOUX, Bruno \& BRUEGEL, Martin. Histoire et identités alimentaires en Europe. France: Hachette Littératures, s.d.

LÉVI-STRAUSS, Claude. Anthropologie structurale. Paris: Plon, 1996.

MACIEL, Maria Eunice. Uma cozinha à brasileira. Estudos Históricos, n. 33, 2004.

MAFFESOLI, Michel.Du nomadisme - vagabondages initiatiques. Paris: Librairie Générale Française, 1997.

MARINHO, Francisco Fernandes. Câmara Cascudo em Portugal e o I Congresso LusoBrasileiro de Folclore. Natal: Nordeste, 2004.

MEUCCI, S. Gilberto Freyre e a sociologia do Brasil: da sistematização à constituição do campo científico. Tese (Doutorado em Sociologia). Universidade Estadual de Campinas, Campinas, 2006.

NAXARA, Márcia Regina Capelari. Estrangeiro em sua própria terra: representações do trabalhador nacional 1870/1920. Dissertação (Mestrado em História) Universidade Estadual de Campinas. Campinas, 1991.

RAMOS, Rui. A ciência do povo e as origens do estado cultural. In: CASTELOBRANCO, Salwa El-Shawn \& BRANCO, Jorge Freitas. Vozes do povo: a folclorização de Portugal. Oeiras: Celta, 2003.
REVEZ, Ricardo. Fialho de Almeida e as correntes estético-literárias no final do século XIX em Portugal. Revista de História das Idéias, Coimbra, vol. 32, 2011.

RIBEIRO, Emanuel. $O$ doce nunca amargou... Doçaria portuguesa. História. Decoração. Receituário. Sintra: Colares Editora, s.d.

ROZIN, Paul . The psychology of food and food choice. In: KIPLE, Kenneth F. \& ORNELAS, Kriemhild Coneè (ed.). The Cambridge world history of food (vol. 2). Cambridge: Cambridge University Press, 2001.

SCHWARCZ, L. M. O espetáculo das raças. Cientistas, instituições e questão racial no Brasil 1870-1930. São Paulo: Companhia das Letras, 1993.

SERRÃO, Joaquim Veríssimo. História de Portugal [1941-1951]. Portugal: Editorial Verbo, 2003.

SERRÃO, Joel \& MARQUES, A. H. de Oliveira (dir.). Nova história de Portugal. Portugal e o Estado Novo (1930-1960). Lisboa: Editorial Presença, 1992.

SHIMABUKURO, Elisabete H.; AZEVEDO, José Eduardo; CARNEIRO, Zélia Maria Ramos; BOTANI, Aparecida Sales Linares (orgs.). Catálogo da Sociedade de Etnografia e Folclore. São Paulo: Centro Cultural de São Paulo, s.d.

SILVA, Marcos. Cultura como patrimônio popular (perspectivas de Câmara Cascudo). Projeto História, São Paulo, n. 33, p. 195-204, dez. 2006.

SOUZA, Ilza Matias de. Câmara Cascudo viajante da escrita e do pensamento nômade. Natal: Editora da UFRN, 2006. 


\title{
Resumo
}

O presente artigo tem como proposta articular experiências individuais na interpretação da cultura coletiva, focalizando a influência de sabores experimentados por Câmara Cascudo em sua viagem a Portugal de 1947 na escrita de sua obra História da alimentação no Brasil, publicada em 1967. Para tanto, parte-se da noção de que o gosto alimentar congrega tanto influências culturais e históricas como experiências individuais.

Nessa perspectiva, apresentam-se fragmentos da memória pessoal de Cascudo e argumentos através dos quais ele defende uma cozinha tradicional brasileira, no sentido de identificar influências de experiências gustativas individuais em sua narrativa histórica alimentar.

Palavras-chave: história da alimentação; Câmara Cascudo; cozinha brasileira; cozinha portuguesa; gosto; tradições alimentares.

\begin{abstract}
The present article aims to articulate individual experiences in the interpretation of collective culture, by means of examining the influence of flavors experienced by Câmara Cascudo in his trip to Portugal in 1947 in his writing of History of food in Brazil. The article is based on the notion that the taste of food carries cultural and historical influences, as well as individual experiences. It presents fragments of Cascudo's personal memories and the arguments with which he defends traditional Brazilian cuisine, in order to identify the influence of individual taste experiences in his history of food. Key words: history of food; Câmara Cascudo; Brazilian cuisine; Portuguese cuisine; taste; food traditions.
\end{abstract}

\section{Résumé}

Cet article veut analyser l'articulation d'expériences individuelles avec l'interprétation de la culture collective, en observant l'influence qu'ont eu les saveurs rencontrées par Câmara Cascudo lors de son voyage au Portugal en 1947 sur l'écriture de son Histoire de l'alimentation au Brésil, publiée en 1967. On part de l'idée que le goût alimentaire rassemble des influences culturelles et historiques, bien que des expériences individuelles. On présente des fragments de la mémoire de Cascudo ainsi que les arguments avec lesquels il défend une cuisine traditionnelle brésilienne, afin d'identifier l'influence des expériences gustatives sur son récit historique.

Mots-clés: histoire de l'alimentation; Câmara Cascudo; cuisine brésilienne; cuisine portugaise; goût; traditions alimentaires. 